Voix et Images

volxetimages

\title{
Index du volume XXXIII
}

Volume 34, numéro 1 (100), automne 2008

Pierre Nepveu

URI : https://id.erudit.org/iderudit/019413ar

DOI : https://doi.org/10.7202/019413ar

Aller au sommaire du numéro

Éditeur(s)

Université du Québec à Montréal

ISSN

0318-9201 (imprimé)

1705-933X (numérique)

Découvrir la revue

Citer ce document

(2008). Index du volume XXXIII. Voix et Images, 34(1), 160-161.

https://doi.org/10.7202/019413ar

Ce document est protégé par la loi sur le droit d'auteur. L'utilisation des services d'Érudit (y compris la reproduction) est assujettie à sa politique d'utilisation que vous pouvez consulter en ligne.

https://apropos.erudit.org/fr/usagers/politique-dutilisation/
Cet article est diffusé et préservé par Érudit.

Érudit est un consortium interuniversitaire sans but lucratif composé de l’Université de Montréal, l'Université Laval et l'Université du Québec à Montréal. Il a pour mission la promotion et la valorisation de la recherche. https://www.erudit.org/fr/ 


\section{INDEX DU VOLUME XXXIII}

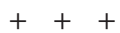

AUBRY, Danielle, "Échos et "survenances" dans les versions médiatiques du Survenant», 3, p. 41-53.

AUGER, Manon, «Forme et formation d'une identitê narrative. La mise en scène de soi dans le Journal (1874-1881)

d'Henriette Dessaulles », 1, p. 115-129.

BEAULIEU, Michel, «Inédit. Le nombril d'autrui et celui de moi-même», 2, p. 1523.

BIRON, Michel, «Le poète de la rue Draper», 2, p. 83-95

BIRON, Michel et Frédéric RONDEAU,

«Les formes fuyantes du présent », 2, p. 913

BOILARD, Joël, Marie-Ëve LANDRY et Sara-Lise ROCHON, «Bibliographie de Germaine Guèvremont», 3, p. 81-93.

BONENFANT, Luc, "La poésie omnivore», 1, p. 164-169; «Platitudes et densités de la poésie contemporaine», 3, p. 124-128.

BOUCHARD, Michel Marc, «Inédit. Soirée bénéfice pour tous ceux qui ne seront pas là en l'an deux mille», 1, p. 31-45.
BROCHU, Andrê, «Deux rêtrospectives

Madeleine Gagnon, Alexis Lefrançois », 1, p. 158-163; "Anthologies», 2, 150-155; «Poèmes et parlure», 3, p. 119-123.

DÉCARIE, David et Lucie JOUBERT,

«Germaine Guèvremont. Nouvelles survenances », 3, p. 9-13

DESTREMPES, Hélène et Jean MORENCY, «Américanitê et modernitê dans le cycle du Survenant », 3, p. 29-40.

DION, Robert, «Ce que deviennent les "classiques"», 1, p. 170-175; «Dont actes», 2, p. 165-170.

FILTEAU, Claude, «Michel Beaulieu, le lyrisme et après ”, 2, p. 37-55; «Un ange cornu avec des ailes de tôle de Michel Tremblay. Les paradoxes de la fiction », 3 , p. $97-110$

FORTIER, Frances, «Le personnage de roman. Parole, corps ou allégorie? ", 1, p. 152-157; «Les ressorts diégétiques du livre ou le livre comme prétexte», 2, 138 143.

GUÈVREMONT, Germaine, «Inédit. Le Survenant", 3, p. 21-27.
HUFFMAN, Shawn, «Entretien avec Michel Marc Bouchard», 1, p. 15-29, «Reliquaire de l'enfance. Espace et sublimation dans L'histoire de l'oie», 1 , p. $83-95$

HUFFMAN, Shawn et Dominique LAFON, «Entre identitê et identitaire», 1, p. 9-14.

JOUBERT, Lucie, «La radio. Un salut pour la toute petite voix de Phonsine?», 3 p. $55-67$.

JOUBERT, Lucie et David DÉCARIE,

«Germaine Guèvremont. Nouvelles survenances », 3, p. 9-13.

LAFON, Dominique, «Le chemin des violences », 1, p. 59-72; "Soirée bénéfice pour tous ceux qui ne seront pas là en l'an deux mille», 1, p. 27-29.

LAFON, Dominique et Shawn HUFFMAN, «Entre identité et identitaire», 1, p. 9-14.

LANDRY, Marie-Ėve, Joël BOILARD et Sara-Lise ROCHON, «Bibliographie de Germaine Guèvremont», 3, p. 81-93. 
LAPOINTE, Martine-Emmanuelle, «Le

syndrome de la fin ", 2, 144-149;

«Enfances romanesques», 3, p. 113-118.

LINTVELT, Jaap, «Le début et la fin de L'enfant chargé de songes d'Anne Hêbert ", 1, p. 131-143.

MARTEL, Jacinthe, "Avant-propos », 1, p. 5-6; «Avant-propos», 2, p. 5-6; «Avantpropos", 3, p. 5-6.

MIRON, Isabelle, «Les dernières traces de Michel Beaulieu », 2, p. 57-67.

MORENCY, Jean et Hélène

DESTREMPES, "Américanitē et modernité dans le cycle du Survenant», 3, p. 29-40.

OLSCAMP, Marcel, «Éditer un texte radiophonique. Problèmes et défis du radioroman Le Survenant», 3, p. 15-20.
O'NEILL-KARCH, Mariel, «Le chemin des Passes-dangereuses. "Rien que des impressions"», 1, p. 73-82.

PARÉ, François, «Histoires de revenances", 1, p. 147-151; «Oiseaux, totems et sémaphores. Verticalitê du poème chez Michel Beaulieu », 2, p. 25-36;

«Mysticismes de l'écrivain », 2, 133-137.

RIENDEAU, Pascal et Sébastien SACRÉ,

«L'êcriture de la torture comme art romanesque. Pensée êthique et création littêraire dans Le maître de jeu de Sergio Kokis», 2, p. 115-130.

ROBERT, Lucie, «L'immortalité du monde. Figures de l'artiste chez Michel Marc Bouchard", 1, p. 47-58; "L'écrivain au thêâtre ", 2, 156-164.

ROCHON, Sara-Lise, Joël BOILARD et Marie-Êve LANDRY, «Bibliographie de Germaine Guèvremont», 3, p. 81-93.
RONDEAU, Frédêric, «La mesure et l'excès. Grammaire de la présence selon Michel Beaulieu », 2, p. 69-81.

RONDEAU, Frédéric et Michel BIRON, "Les formes fuyantes du présent », 2, p. 913; «Bibliographie de Michel Beaulieu », 2, 97-112.

ROY, Sébastien, «Bibliographie de Michel Marc Bouchard», 1, p. 97-112.

SACRÉ, Sébastien et Pascal RIENDEAU,

«L'écriture de la torture comme art romanesque. Pensée êthique et création littêraire dans Le maître de jeu de Sergio Kokis», 2, p. 115-130.

SAINT-MARTIN, Lori, " “Se donner les coups qui portent". Sexe, pouvoir et parole dans le radioroman Le Survenant », 3, p. $69-80$ 